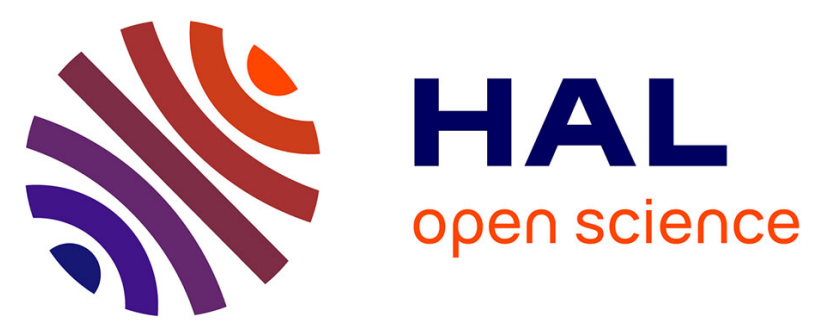

\title{
Lack of prognostic significance of "classic" lobular breast carcinoma: a matched, single institution series
}

Giuseppe Viale, Nicole Rotmensz, Patrick Maisonneuve, Enrico Orvieto, Eugenio Maiorano, Viviana Galimberti, Alberto Luini, Marco Colleoni, Aron Goldhirsch, Alan S. Coates

\section{To cite this version:}

Giuseppe Viale, Nicole Rotmensz, Patrick Maisonneuve, Enrico Orvieto, Eugenio Maiorano, et al.. Lack of prognostic significance of "classic" lobular breast carcinoma: a matched, single institution series. Breast Cancer Research and Treatment, 2008, 117 (1), pp.211-214. 10.1007/s10549-008-01124. hal-00486592

\section{HAL Id: hal-00486592 https://hal.science/hal-00486592}

Submitted on 26 May 2010

HAL is a multi-disciplinary open access archive for the deposit and dissemination of scientific research documents, whether they are published or not. The documents may come from teaching and research institutions in France or abroad, or from public or private research centers.
L'archive ouverte pluridisciplinaire HAL, est destinée au dépôt et à la diffusion de documents scientifiques de niveau recherche, publiés ou non, émanant des établissements d'enseignement et de recherche français ou étrangers, des laboratoires publics ou privés. 


\title{
Lack of prognostic significance of "classic" lobular breast carcinoma: a matched, single institution series
}

\author{
Giuseppe Viale $\cdot$ Nicole Rotmensz $\cdot$ Patrick Maisonneuve $\cdot$ Enrico Orvieto $\cdot$ \\ Eugenio Maiorano - Viviana Galimberti · Alberto Luini · Marco Colleoni · \\ Aron Goldhirsch · Alan S. Coates
}

Received: 24 June 2008/Accepted: 24 June 2008/Published online: 16 July 2008

(C) Springer Science+Business Media, LLC. 2008

\begin{abstract}
Whether invasive lobular carcinoma of the breast per se constitutes a prognostically favorable type has been debated. The present series comprises 301 consecutive "classic" lobular breast carcinomas seen at one institution between 1994 and 2001, compared to an equal number of invasive ductal carcinomas at the same institution during the same period, matched for year of surgery, age, menopausal status, primary tumor size, nodal involvement, hormone receptor status and where possible histological grade. Despite matching, the lobular carcinomas were more frequently multifocal, had more involved nodes, lower grade
\end{abstract}

\author{
G. Viale $(\bowtie)$ \\ Division of Pathology and Laboratory Medicine, European \\ Institute of Oncology, University of Milan, Via Ripamonti, 435, \\ 20141 Milan, Italy \\ e-mail: giuseppe.viale@ieo.it \\ N. Rotmensz $\cdot$ P. Maisonneuve \\ Division of Epidemiology and Biostatistics, \\ European Institute of Oncology, Milan, Italy \\ e-mail: nicole.rotmensz@ieo.it \\ P. Maisonneuve \\ e-mail: patrick.maisonneuve@ieo.it \\ E. Orvieto \\ Section of Anatomical Pathology, Department of Oncological \\ and Surgical Sciences, University of Padova, Padova, Italy \\ e-mail: enrico.orvieto@sanita.padova.it \\ E. Maiorano \\ Department of Pathological Anatomy, University of Bari, \\ Bari, Italy \\ e-mail: emaiorano@anatopat.uniba.it \\ V. Galimberti · A. Luini \\ Division of Breast Surgery, European Institute of Oncology, \\ Milan, Italy \\ e-mail: viviana.galimberti@ieo.it
}

and lower proliferative fraction. There was no significant difference in disease-free or overall survival, locoregional relapse or time to distant metastasis between the lobular and ductal groups overall or within any examined subset, though the lobular group showed a trend to earlier appearance of contralateral breast cancer. Classical lobular histology is not an independent factor in the prognosis of early breast cancer.

Keywords Breast cancer - Lobular carcinoma . Prognosis · Matched study

\author{
A. Luini \\ e-mail: alberto.luini@ieo.it \\ M. Colleoni \\ Division of Medical Oncology, European Institute of Oncology, \\ Milan, Italy \\ e-mail: marco.colleoni@ieo.it
}

A. Goldhirsch

European Institute of Oncology, Milan, Italy

e-mail: aron.goldhirsch@ibcsg.org

A. Goldhirsch

Oncology Institute of Southern Switzerland, Bellinzona,

Switzerland

\section{A. S. Coates}

International Breast Cancer Study Group, Bern, Switzerland e-mail: alan.coates@ibcsg.org

A. S. Coates

University of Sydney, Sydney, Australia 


\section{Introduction}

Carcinoma of the breast may be classified according to their presumed origin from epithelial cells of the secretory lobules or those lining the draining ducts. Pathologists have long recognized specific patterns among breast cancers, but the majority lack these features and are classified as infiltrating ductal carcinomas (IDC) not otherwise specified. Invasive lobular cancers (ILC) are the second most common type, constituting 5-16\% of all breast cancer [1-3]. Based on a variety of study designs, some previous authors have concluded that ILC carries a favorable prognosis compared to IDC [4-8], while others have found the outcome of the two groups to be similar [9-19]. In two recent studies with prolonged follow-up, it was noted that the disease-free and overall survival curves crossed, with an initial favorable and later unfavorable impact of ILC type [20, 21].

Several previous series have used a matched design to allow for imbalances of prognostic factors other than ILC type [4, 9, 10, 17, 22]. Among series which compared unmatched groups of ILC and IDC, ILC has been associated with larger primary tumor size $[5,8,13,15,16,18,20]$; most $[5,13,15,16]$ but not all [12] have reported higher expression of hormone receptors, while the degree of nodal involvement has variously been noted as less [16, 21], similar [12] or greater [5]. There is uniform agreement that the organ distribution of metastatic disease tends to be different, with ILC displaying a tendency to metastasize to the gastrointestinal tract, pelvic organs and retroperitoneum [9, 10, 13, 23].

\section{The experience at the European Institute of Oncology (IEO)}

The present series is based on an earlier report of 530 cases of ILC [24] from this institution, describing the more favorable outcome of the classic subtype of ILC as distinct from alveolar, solid, pleomorphic, signet ring histiocytoid or apocrine variants. The 301 cases of classic ILC identified in that study were matched 1:1 with cases of IDC treated at the institution during the same period based on year of surgery, age, menopausal status, primary tumor size, lymph node involvement, hormone receptor status and when possible tumor grade. Matching between the groups was close for most variables with the exceptions that the ILC group had more frequent multifocality $(P<0.001)$; more involved lymph nodes $(P=0.001)$; a lower proliferative fraction as measured by ki67 labeling index [25, 26] $(P=0.005)$; and a higher proportion of histological grade I tumors $(P=0.022)$.

As has been described by others [9, 10, 13, 23], we observed a different pattern of distribution of metastases between the groups, in that ILC was associated with more metastases to the gastrointestinal tract and pelvic organs. Median follow up was 7.3 years (7.8 years for IDC, 7.0 years for ILC). Disease-free and overall survival curves as well as time to locoregional relapse, distant metastasis, contralateral breast cancer and the appearance of other (non-breast) cancer were prepared for each group by the Kaplan-Meier method and compared by the log rank test. For none of these endpoints was there any significant difference between the ILC and IDC groups. Effects within subgroups defined by age, menopausal status, primary tumor size, multifocality, nodal status, histological grade, hormone receptor status, ki67 labeling index, type of surgery and adjuvant systemic therapy were compared using Cox proportional hazard models. No subgroup showed effects on disease-free or overall survival significantly different from the overall result (Fig. 1).

We conclude that, once allowance is made for routinely collected prognostic factors, the outcome of classic ILC does not differ significantly from IDC (Table 1).
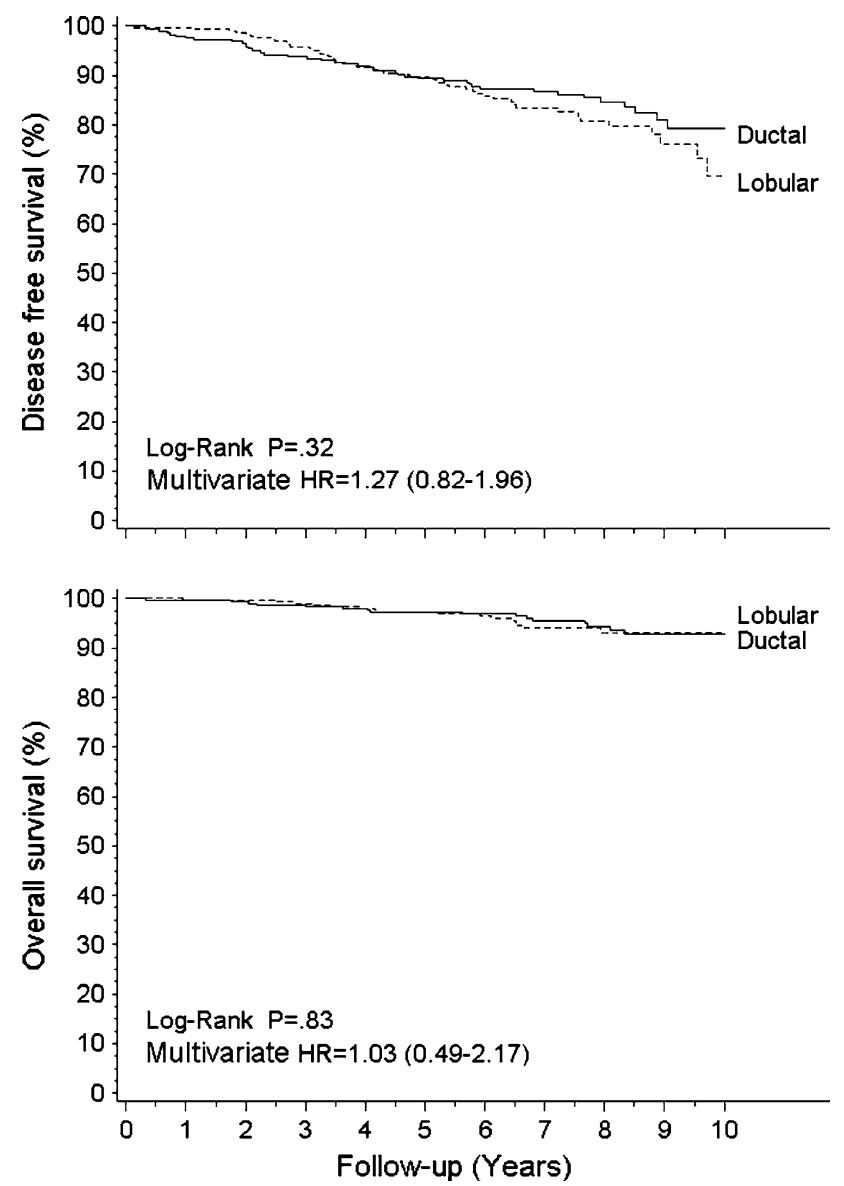

Fig. 1 Disease-free survival (top) and overall survival (below) curves comparing classic infiltrating lobular carcinoma with infiltrating ductal carcinoma. Hazards Ratios (HR) and 95\% confidence intervals obtained from multivariate Cox proportional hazards regression model adjusted for age, pT, pN, multifocality, grade, hormonal receptor status, ki67 and type of surgery 
Table 1 Patient and tumor characteristics

\begin{tabular}{|c|c|c|c|c|c|}
\hline \multirow{2}{*}{$\begin{array}{l}\text { Table } 1 \text { Patient and tumor } \\
\text { characteristics }\end{array}$} & & \multirow[t]{2}{*}{ All patients } & \multicolumn{2}{|c|}{ Classical } & \multirow[t]{2}{*}{$P$-value } \\
\hline & & & Ductal & Lobular & \\
\hline & All patients & 602 & 301 & 301 & \\
\hline & \multicolumn{5}{|l|}{ Age group } \\
\hline & $<40$ & $32(5.3 \%)$ & 16 & 16 & \\
\hline & $40-49$ & $147(24.4 \%)$ & 70 & 77 & \\
\hline & $50-59$ & $217(36.0 \%)$ & 114 & 103 & \\
\hline & $60-69$ & $140(23.3 \%)$ & 70 & 70 & \\
\hline & $70+$ & $66(11.0 \%)$ & 31 & 35 & $0.97^{\mathrm{a}}$ \\
\hline & \multicolumn{5}{|l|}{ Menopausal status } \\
\hline & Pre/peri-menopausal & $218(36.2 \%)$ & 109 & 109 & \\
\hline & Post-menopausal & $184(63.8 \%)$ & 192 & 192 & 1.00 \\
\hline & \multicolumn{5}{|l|}{$\mathrm{pT}$} \\
\hline & pT1 & $390(64.8 \%)$ & 195 & 195 & \\
\hline & pT2 & $168(27.9 \%)$ & 86 & 82 & \\
\hline & pT3-pT4 & $44(7.3 \%)$ & 20 & 24 & $0.79^{\mathrm{a}}$ \\
\hline & \multicolumn{5}{|l|}{ Multifocality } \\
\hline & Monofocal & $465(77.2 \%)$ & 256 & 209 & \\
\hline & Multifocal & $137(22.8 \%)$ & 45 & 92 & $<\mathbf{0 . 0 0 0 1}$ \\
\hline & \multicolumn{5}{|l|}{$\mathrm{pN}$} \\
\hline & pN0 (AD) & $177(29.4 \%)$ & 92 & 85 & \\
\hline & Sentinel node negative & $189(31.4 \%)$ & 101 & 88 & \\
\hline & $\mathrm{pN}+$ & $212(35.2 \%)$ & 106 & 106 & 0.79 \\
\hline & $\mathrm{pNx}$ & $24(4.0 \%)$ & 2 & 22 & \\
\hline & \multicolumn{5}{|l|}{ Number of positive nodes } \\
\hline & None & $366(60.8 \%)$ & 193 & 173 & \\
\hline & $1-3$ & $141(23.4 \%)$ & 78 & 63 & \\
\hline & $4-10$ & $43(7.1 \%)$ & 23 & 20 & \\
\hline & $>10$ & $28(4.7 \%)$ & 5 & 23 & $0.001^{\mathrm{a}}$ \\
\hline & $\mathrm{pNx}$ & $24(4.0 \%)$ & 2 & 22 & \\
\hline & \multicolumn{5}{|l|}{ Tumor grade } \\
\hline & Grade 1 & $319(53.0 \%)$ & 145 & 174 & \\
\hline & Grade 2 & $283(47.0 \%)$ & 156 & 127 & 0.022 \\
\hline & \multicolumn{5}{|l|}{ Hormone receptors status } \\
\hline & Estrogen \& progesterone receptor negative & $31(5.1 \%)$ & 15 & 16 & \\
\hline & Estrogen or progesterone receptor positive & $571(94.9 \%)$ & 286 & 285 & 0.85 \\
\hline & \multicolumn{5}{|l|}{ Proliferative fraction } \\
\hline & ki67 labeling index $<20 \%$ & $471(78.2 \%)$ & 222 & 249 & \\
\hline & ki67 labeling index $\geq 20 \%$ & $129(21.4 \%)$ & 79 & 50 & 0.005 \\
\hline & Unknown & $2(0.3 \%)$ & 0 & 2 & \\
\hline & \multicolumn{5}{|l|}{ Type of surgery } \\
\hline & Breast conserving surgery & $467(77.6 \%)$ & 243 & 224 & \\
\hline & Total mastectomy & $135(22.4 \%)$ & 58 & 77 & 0.078 \\
\hline & \multicolumn{5}{|l|}{ Type of adjuvant systemic therapy } \\
\hline & None & $39(6.5 \%)$ & 26 & 13 & \\
\hline & Endocrine alone & $320(53.2 \%)$ & 150 & 170 & \\
\hline & Non-anthracycline & $143(23.8 \%)$ & 74 & 69 & \\
\hline Trend & Anthracycline & $87(14.5 \%)$ & 41 & 46 & 0.11 \\
\hline Bold values indicate statistically & Unknown & $13(2.2 \%)$ & 10 & 3 & \\
\hline
\end{tabular}

a Trend

Bold values indicate statistically significant values 


\section{References}

1. Fisher ER, Gregorio RM, Fisher B et al (1975) The pathology of invasive breast cancer. A syllabus derived from findings of the National Surgical Adjuvant Breast Project (protocol no 4). Cancer 36:1-85. doi:10.1002/1097-0142(197507)36:1<1::AIDCNCR2820360102>3.0.CO;2-4

2. Ellis IO, Galea M, Broughton N et al (1992) Pathological prognostic factors in breast cancer. II. Histological type. Relationship with survival in a large study with long-term follow-up. Histopathology 20:479-489

3. Martinez V, Azzopardi JG (1979) Invasive lobular carcinoma of the breast: incidence and variants. Histopathology 3:467-488. doi:10.1111/j.1365-2559.1979.tb03029.x

4. du Toit RS, Locker AP, Ellis IO et al (1991) An evaluation of differences in prognosis, recurrence patterns and receptor status between invasive lobular and other invasive carcinomas of the breast. Eur J Surg Oncol 17:251-257

5. Cristofanilli M, Gonzalez-Angulo A, Sneige N et al (2005) Invasive lobular carcinoma classic type: response to primary chemotherapy and survival outcomes. J Clin Oncol 23:41-48. doi:10.1200/JCO.2005.03.111

6. Dian D, Herold H, Mylonas I et al (2008) Survival analysis between patients with invasive ductal and invasive lobular breast cancer. Arch Gynecol Obstet. doi:10.1007/s00404-008-0662-z

7. Toikkanen S, Pylkkanen L, Joensuu H (1997) Invasive lobular carcinoma of the breast has better short- and long-term survival than invasive ductal carcinoma. Br J Cancer 76:1234-1240

8. Silverstein MJ, Lewinsky BS, Waisman JR et al (1994) Infiltrating lobular carcinoma. Is it different from infiltrating duct carcinoma? Cancer 73:1673-1677. doi:10.1002/1097-0142 (19940315)73:6<1673::AID-CNCR2820730620>3.0.CO;2-B

9. Casolo P, Raspadori A, Drei B et al (1997) Natural history of breast cancer: lobular carcinoma versus ductal carcinoma in our experience. Ann Ital Chir 68:43-47

10. Fondrinier E, Guerin O, Lorimier G (1997) A comparative study of metastatic patterns of ductal and lobular carcinoma of the breast from two matched series (376 patients). Bull Cancer 84:1101-1107

11. Winchester DJ, Chang HR, Graves TA et al (1998) A comparative analysis of lobular and ductal carcinoma of the breast: presentation, treatment, and outcomes. J Am Coll Surg 186:416422. doi:10.1016/S1072-7515(98)00051-9

12. Mersin H, Yildirim E, Gulben K et al (2003) Is invasive lobular carcinoma different from invasive ductal carcinoma? Eur J Surg Oncol 29:390-395. doi:10.1053/ejso.2002.1423

13. Arpino G, Bardou VJ, Clark GM et al (2004) Infiltrating lobular carcinoma of the breast: tumor characteristics and clinical outcome. Breast Cancer Res 6:R149-R156. doi:10.1186/bcr767
14. Santiago RJ, Harris EE, Qin L et al (2005) Similar long-term results of breast-conservation treatment for Stage I and II invasive lobular carcinoma compared with invasive ductal carcinoma of the breast: The University of Pennsylvania experience. Cancer 103:2447-2454. doi:10.1002/cncr.21071

15. Gonzalez-Angulo AM, Sahin A, Krishnamurthy S et al (2006) Biologic markers in axillary node-negative breast cancer: differential expression in invasive ductal carcinoma versus invasive lobular carcinoma. Clin Breast Cancer 7:396-400

16. Tubiana-Hulin M, Stevens D, Lasry S et al (2006) Response to neoadjuvant chemotherapy in lobular and ductal breast carcinomas: a retrospective study on 860 patients from one institution. Ann Oncol 17:1228-1233. doi:10.1093/annonc/mdl114

17. Ni MJ, Curran C, Hennessy E et al (2008) Prospective matchedpair comparison of outcome after treatment for lobular and ductal breast carcinoma. Br J Surg. doi:10.1002/bjs.6042

18. Molland JG, Donnellan M, Janu NC et al (2004) Infiltrating lobular carcinoma-a comparison of diagnosis, management and outcome with infiltrating duct carcinoma. Breast 13:389-396. doi:10.1016/j.breast.2004.03.004

19. Jayasinghe UW, Bilous AM, Boyages J (2007) Is survival from infiltrating lobular carcinoma of the breast different from that of infiltrating ductal carcinoma? Breast J 13:479-485. doi:10.1111/j. 1524-4741.2007.00468.x

20. Pestalozzi BC, Zahrieh D, Mallon E et al (2008) Distinct clinical and prognostic features of infiltrating lobular carcinoma of the breast: combined results of 15 international breast cancer study group clinical trials. J Clin Oncol. doi:10.1200/JCO.2007.14.9336

21. Rakha EA, El-Sayed ME, Powe DG et al (2008) Invasive lobular carcinoma of the breast: response to hormonal therapy and outcomes. Eur J Cancer 44:73-83. doi:10.1016/j.ejca.2007.10.009

22. Sinha PS, Bendall S, Bates T (2000) Does routine grading of invasive lobular cancer of the breast have the same prognostic significance as for ductal cancers? Eur J Surg Oncol 26:733-737. doi:10.1053/ejso.2000.0994

23. Borst MJ, Ingold JA (1993) Metastatic patterns of invasive lobular versus invasive ductal carcinoma of the breast. Surgery 114:637-641

24. Orvieto E, Maiorano E, Bottiglieri L et al (2008) Clinico-pathological characteristics of invasive lobular carcinoma of the breast: results of an analysis of 530 cases from a single institution. Cancer (in press)

25. Lehr HA, Hansen DA, Kussick S et al (1999) Assessment of proliferative activity in breast cancer: MIB-1 immunohistochemistry versus mitotic figure count. Hum Pathol 30:13141320. doi:10.1016/S0046-8177(99)90062-X

26. Thor AD, Liu S, Moore DH et al (1999) Comparison of mitotic index, in vitro bromodeoxyuridine labeling, and MIB-1 assays to quantitate proliferation in breast cancer. J Clin Oncol 17:470-477 